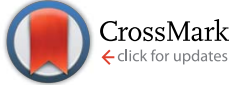

Cite this: RSC Adv., 2016, 6, 59502
Received 20th April 2016

Accepted 10th June 2016

DOI: 10.1039/c6ra10250f

www.rsc.org/advances

\title{
Self-assembly of fluorescent diimidazolium salts: tailor properties of the aggregates changing alkyl chain features $\uparrow$
}

\author{
Floriana Billeci, Francesca D'Anna, ${ }^{*}$ Salvatore Marullo and Renato Noto \\ Searching for new fluorescent organic salts to be used in biomedical and electrochemical field, we \\ conjugated properties of imidazolium salts with the ones of naphthalene diimide core and we obtained \\ some $N, N^{\prime}$-bis-(1-alkyl-3-propylimidazolium)naphthalene diimide diiodides. We took into account alkyl \\ chains going from hexyl to dodecyl, as well as hydrogenated and fluorinated alkyl tails. After \\ determination of their thermal behaviour by differential scanning calorimetry, concentration-, and \\ temperature-dependent spectroscopic studies (UV-vis and fluorescence) were performed evidencing the \\ occurrence of isodesmic and enthalpy-driven self-assembly processes. Properties of aggregates were \\ also investigated in the solid state by fluorescence spectroscopy and scanning electron microscopy \\ (SEM). Information obtained evidenced the formation of $\mathrm{H}$-aggregates that are organized in spherical or \\ disk-like structures.
}

\section{Introduction}

Self-assembled materials are the object of an intense interest, stretching from aggregates observed in natural systems, to the wide range of application of synthetic ones. Both share the emergence of peculiar properties from the reversible and spontaneous association of molecular building blocks. ${ }^{1}$

Hence, self-assembly is a viable route to obtain nanostructures and smart materials, which can be employed in different technological fields, spanning from biosensing, optoelectronics, to solar cells..$^{2-5}$ In this context, the most promising self-assembled materials appear to be based on $\pi$-conjugated molecules endowed with extended aromatic nuclei and welldefined redox properties. These include oligophenylenevinylenes, oligophenyleneethylenes, oligothiophenes, perylenediimides and naphthalene diimides. ${ }^{6-8}$

The principal non-covalent interactions involved in the formation of their aggregates are $\pi-\pi$ stacking between aromatic surfaces and hydrogen bonds. However, in these selfassembly processes both solvent system and substituents take on key roles.

The strong link between monomer structure and properties of the aggregates is manifested in the possible formation of $\mathrm{J}$ and $\mathrm{H}$ aggregates, ${ }^{9,10}$ where the aromatic nuclei are staggered

Dipartimento STEBICEF, Sezione di Chimica, Viale delle Scienze, Ed. 17, 90128 Palermo, Italy. E-mail: francesca.danna@unipa.it

$\dagger$ Electronic supplementary information (ESI) available: Synthetic procedures and compounds characterization. UV-vis, fluorescence and NMR spectra. SEM images. See DOI: $10.1039 / \mathrm{c} 6 \mathrm{ra10250f}$ along the longitudinal axis of the molecule or arranged in parallel, respectively.

Among the various aromatic nuclei able to self-assemble, a pivotal role is exerted by naphthalene diimides (NDIs). Their structural features are suitable for several applications, such as n-type organic semiconductors, optoelectronics, organic solar cells and the organic light emitting diodes. ${ }^{11}$ Indeed, accessible $\pi$ orbitals and extended charge delocalization area facilitate charge transfer. ${ }^{12,13}$ Other interesting applications show NDI used in biomedical field, as charge device and DNA intercalators. ${ }^{12,14-16}$ In the last case, the NDI moiety allows the formation of aggregates and, as a consequence, the interaction between biosensor and DNA. ${ }^{15}$ The particular redox properties of the NDI nucleus allow its derivates to be used also as electronic scaffolds in lipid bilayers. ${ }^{17}$ Furthermore, NDI has been used to analyse the role of DNA-G-quartet/quadruplex core in the charge transfer. These additional examples confirm the versatile features of these systems. ${ }^{18}$

To date, the study of these systems has been mainly focused on neutral NDIs. To the best of our knowledge, only two reports have taken in consideration viologen derivatives bearing NDI core, able to form supra-amphiphiles to be used in optoelectronic systems. ${ }^{19,20}$ This raises an important question: what would be the utility of preparing new organic salts having NDI core?

The presence of cationic heads on this electron deficient core could be crucial in all the applications in which coulombic interactions play a pivotal role, like biomedical and energetic materials. In the first case, these derivatives should provide charged species able to interact with polyanions like DNA avoiding the need to prepare metal complexes. As far as the use 
as semiconductors is concerned, organic salts based on NDI bearing in their structure the support electrolyte should reduce the use of more corrosive inorganic salts.

In the last few years, there has been a growing interest in the obtainment of fluorescent organic salts and in particular of dicationic ones. ${ }^{21}$ Data so far reported evidence their high thermal stability, up to about $300{ }^{\circ} \mathrm{C}$, their good solubility in common organic solvents and the possibility to obtain from them fibres and thin films, similar to amorphous polymers. Differently from these latter, organic salts avoid the use of complex synthetic protocols and their properties as well as their applications can be finely tuned bringing about small changes on the cation or anion structure.

Aggregation of organic salts both in solution and in solid state is generally characterized by the emission of blue light. In some cases they have shown chemical behaviour typical of ionic liquids and liquid crystals. ${ }^{\mathbf{1 2 , 2 2 , 2 3}}$ Moreover, it has been demonstrated that the presence of charges in the molecule can improve both the aggregation ability and electronic properties through the electrostatic interaction, increasing the life time of charge-separated state. ${ }^{19,24}$

Bearing this in mind, in the framework of our interest in the aggregation ability of diimidazolium salts endowed with an aromatic spacer, ${ }^{\mathbf{6}, 25}$ we decided to combine the well-known properties of imidazolium salts with the ones of NDI core. Then, we herein report a study of the self-assembly ability of several $N, N^{\prime}$-bis-(1-alkyl-3-propylimidazolium)naphthalene diimide iodides ([ $\left.\left.\mathbf{C}_{\boldsymbol{n}} \mathbf{N D I}\right][\mathbf{I}]\right)$ (Chart 1) with the aim to answer two main questions: (i) how the alkyl chain length affects their selfassembly ability? (ii) Is the substitution of hydrogenated by fluorinated tails able to induce significant changes in their selfassembly ability?

To these aims, alkyl tails going from hexyl to dodecyl have been taken into account. This should allow evaluating the influence of van der Waals interactions on the formation of aggregates. Indeed, longer chains should enhance aggregation, but at the same time may interfere with the core $\pi-\pi$ stacking, thus destabilizing the aggregates. ${ }^{26,27}$

Fluorinated alkyl chains have also been taken into account. It is noteworthy that the presence of these chains often increases the thermal stability of substrates, affects their flexibility and could also lead to mesophases. ${ }^{28,29}$ Moreover, long fluorinated alkyl chains, such as those in $\left[\mathbf{C}_{\mathbf{8}} \mathbf{F N D I}\right][\mathbf{I}]$ and $\left[\mathbf{C}_{\mathbf{1 2}} \mathbf{F N D I}\right][\mathbf{I}]$ should increase the hydrophobic character of the system. ${ }^{30}$

Firstly, we analysed the thermal properties of all salts by means of Differential Scanning Calorimetry (DSC)
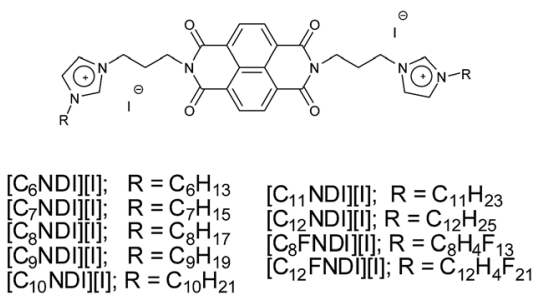

Chart 1 Diimidazolium NDI salts studied. measurements. Then, we tested the aggregation properties of our salts in a wide range of solvents by UV-vis and fluorescence measurements. We carried out concentration dependent UV-vis and fluorescence measurements in all solvents supporting aggregation of the salts. To obtain additional information on the importance of hydrogen bonding on the aggregates formation, we also analysed the effect of the addition of a protic solvent like methanol.

The thermodynamic parameters relating to the aggregation processes were determined by temperature dependent UV-vis analysis. Variable temperature ${ }^{1} \mathrm{H}$ NMR investigations allowed us to identify the protons more involved in the aggregation process.

Finally, the solid phase properties of systems were analysed through fluorescence spectra and SEM images.

\section{Results and discussion}

\section{Synthesis of diimidazolium NDI salts}

Our dicationic organic salts were synthesized using a two-step procedure. In the first step, the 1,4,5,8-naphthalene tetracarboxylic anhydride (NDA) was reacted with a small excess of 3aminopropylimidazole (2.2 eq.) in DMF solution at $140{ }^{\circ} \mathrm{C}$, according to a previous reported procedure (Scheme 1). ${ }^{31}$

This allowed us to obtain the $N, N^{\prime}$-bis-(3-imidazol-yl-propyl)NDI (1) in good yield. The following alkylation of (1) was carried out using a stoichiometric amount (2 eq.) of alkyl iodide in DMF solution at $90{ }^{\circ} \mathrm{C}$ (Scheme 2).

Solvent removal under vacuum and treatment of crude product with diethyl ether under ultrasound irradiation allowed us to obtain reaction products with high yields (details of synthetic procedures and full compounds characterization are reported in ESI $\dagger$ ).

\section{Thermal behaviour}

The thermal behaviour of our organic salts was investigated performing DSC measurements. Traces of heat-cool cycles obtained are reported in Fig. S1. $\dagger$ With the only exception of $\left[\mathbf{C}_{10} \mathbf{N D I}\right][\mathbf{I}]$ (Fig. S1 $\dagger$ ), in all the other cases, in the heating cycle we observed transitions that were ascribed to melting processes. The melting temperatures and enthalpies were determined respectively from the maximum of the signal and from its area. In confirmation of this, observation of the salts using a polarized optical microscope (POM) allowed us to rule out mesophases formation, and by heating we obtained isotropic solutions. The trend of melting temperatures $\left(T_{\mathrm{m}}\right)$ as a function of the number of methylene units in the alkyl chain $\left(n_{\mathrm{CH}_{2}}\right)$ is shown in Fig. 1. Furthermore, $T_{\mathrm{m}}$ are reported in Table $\mathrm{S} 1, \dagger$ together with enthalpy $\left(\Delta H_{\mathrm{m}}\right)$ and entropy $\left(\Delta S_{\mathrm{m}}\right)$ variations.

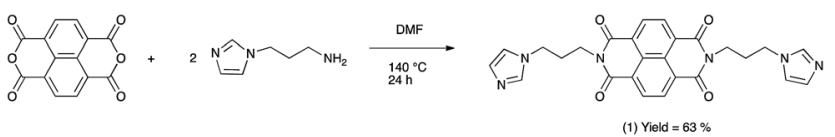

Scheme 1 

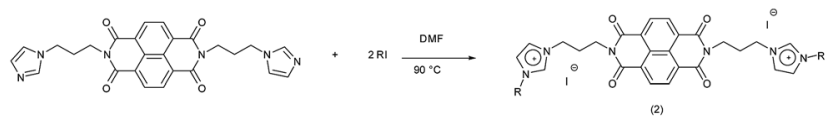

(2)

2a $\left[\mathrm{C}_{6} \mathrm{NDI}\right][1] ; \quad \mathrm{R}=\mathrm{C}_{6} \mathrm{H}_{13}$ Yield $=90 \%$ $2 \mathrm{~b}\left[\mathrm{C}_{7} \mathrm{NDI}\right][1] ; \quad \mathrm{R}=\mathrm{C}_{7} \mathrm{H}_{15}$ Yield $=87 \%$ $\begin{array}{ll}2 \mathrm{c}\left[\mathrm{C}_{8} \mathrm{NDI}\right][1] ; & \mathrm{R}=\mathrm{C}_{8} \mathrm{H}_{1} \text { Yield }=83 \% \\ 2 \mathrm{~d}[\mathrm{C} 9 \mathrm{NDI}[1] ; & \mathrm{R}=\mathrm{C}_{9} \mathrm{H}_{19} \text { Yield }=85 \%\end{array}$ $2 \mathrm{~d}\left[\mathrm{C}_{10} \mathrm{NDI}\right][1] ; \mathrm{R}=\mathrm{C}_{10} \mathrm{H}_{21}$ Yield $=85 \%$ $2 \mathrm{f}\left[\mathrm{C}_{11} \mathrm{NDI}\right][\mathrm{II}] ; \mathrm{R}=\mathrm{C}_{11} \mathrm{H}_{23}$ Yield $=88 \%$ $2 \mathrm{~g}\left[\mathrm{C}_{12} \mathrm{NDI}\right][\mathrm{I}] ; \mathrm{R}=\mathrm{C}_{12} \mathrm{H}_{25}$ Yield $=88 \%$ $2 \mathrm{~h}\left[\mathrm{C}_{8} \mathrm{FNDI}\right][1] ; \mathrm{R}=\mathrm{C}_{8} \mathrm{H}_{4} \mathrm{~F}_{13}$ Yield $=81 \%$
$2 \mathrm{i}\left[\mathrm{C}_{12} \mathrm{FNDI}\right][1] ; \mathrm{R}=\mathrm{C}_{12} \mathrm{H}_{4} \mathrm{~F}_{21}$ Yield $=50 \%$

Scheme 2
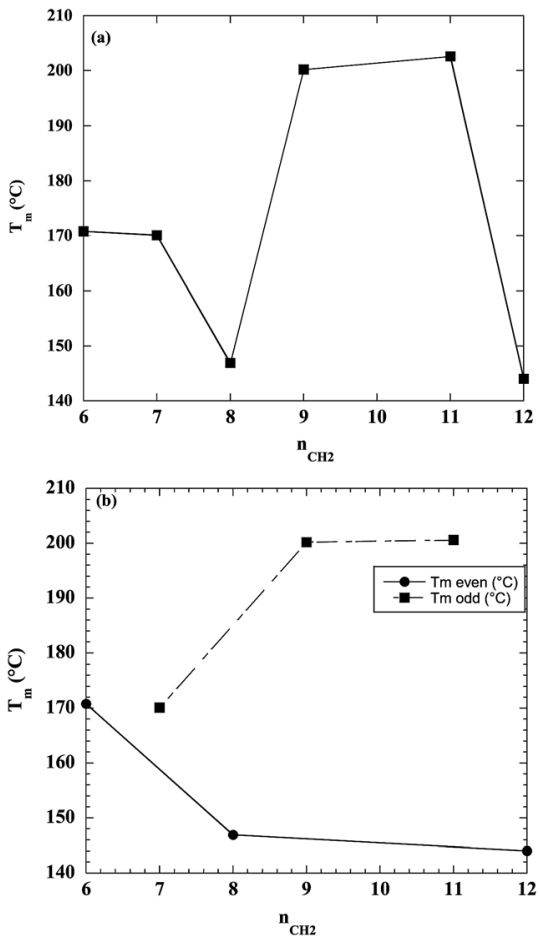

Fig. 1 Plots of (a) melting temperature $\left(T_{\mathrm{m}}\right)$ as a function of $n_{\mathrm{CH}_{2}}$ and (b) odd-even distribution.

Analysis of values collected indicates a certain effect of alkyl chain length on the melting temperature. The trend detected was quite complex. The above trend results more clear if data are analysed as a function of the odd or even number of methylene units in the alkyl chain. Indeed, opposite trends were detected for the two series. For odd terms, $T_{\mathrm{m}}$ increase with the increase in the number of methylene units. On the other hand, as for the even terms, $T_{\mathrm{m}}$ gradually decrease on going from $\left[\mathbf{C}_{\mathbf{6}} \mathbf{N D I}\right][\mathbf{I}]$ to $\left[\mathbf{C}_{\mathbf{1 2}} \mathbf{N D I}\right][\mathbf{I}]$. Interestingly, a divergence among the above trends can be detected at higher number of methylene units (Fig. 1b). The odd-even effect has been already used by Desiraju et $a l^{32}$ to explain the trend of some physico-chemical properties like the elastic modulus and melting temperature of $\alpha, \omega$-alkane dicarboxylic acids. In that case, the divergence between even and odd terms occurred at low number of methylene units. Also in the series of ionic liquids this effect has proved to be crucial in determining trend of density and experimental molar volume of alkylphosphonium and imidazolium salts. ${ }^{33}$
Thermodynamic parameters corresponding to melting process indicate that, for even terms, a decrease in $T_{\mathrm{m}}$ values as a function of alkyl chain length is the result of a corresponding increase in $\Delta S_{\mathrm{m}}$ values. This accounts for a more extensive association of molecules in the solid state for salts with longer alkyl chains. On the contrary, the entropic contribution becomes unfavourable in the case of odd terms and induces the increase in $T_{\mathrm{m}}$.

Fluorination of the alkyl chain causes an increase in $T_{\mathrm{m}}$ values, as accounted for by the comparison among data collected for $\left[\mathbf{C}_{8} \mathbf{N D I}\right][\mathbf{I}]$ and $\left[\mathbf{C}_{8} \mathbf{F N D I}\right][\mathbf{I}]$ or $\left[\mathbf{C}_{12} \mathbf{N D I}\right][\mathbf{I}]$ and $\left[\mathbf{C}_{\mathbf{1 2}} \mathbf{F N D I}\right][\mathbf{I}]$. Thermodynamic parameters indicate that the increase is mainly determined by an enthalpic contribution. This result agrees with the one previously reported about tribological properties of geminal dicationic organic salts bearing fluorinated alkyl spacer. ${ }^{34}$ Furthermore, more recently the above effect has been also detected comparing $T_{\mathrm{m}}$ of imidazolium ionic liquids having alkyl and perfluoroalkyl side chains, ${ }^{35}$ and it has been ascribed to different segregation of non polar hydrogenated and perfluorinated regions.

\section{Spectroscopic investigation}

Spectroscopic properties of our organic salts were investigated using UV-vis and fluorescence measurements. In particular, their photophysical behaviour was firstly analysed in solvents having different polarities and hydrogen bond donor abilities, like acetone, acetonitrile (ACN), chloroform $\left(\mathrm{CHCl}_{3}\right)$, 1,4dioxane (1,4-Diox), $N, N$-dimethylformamide (DMF) and tetrahydrofuran (THF). UV-vis and fluorescence spectra of solutions at a fixed concentration $\left(5 \times 10^{-5} \mathrm{M}\right)$ as a function of solvent are reported in Fig. 2 and $\mathrm{S} 2 . \dagger$

UV-vis spectra show two main absorption bands located at $\sim 354$ and $374 \mathrm{~nm}$ and a shoulder at $\sim 340 \mathrm{~nm}$. The position of these bands was barely affected by solvent nature and the attempt to correlate $\lambda_{\max }$ with solvent polarity gave no regular trend, but evidenced on the whole an hypsochromic shift ( $\sim 3-4$ $\mathrm{nm})$ with the increase in solvent polarity. In some cases $(1,4-$ Diox, THF and DMF), we observed a significant hypochromic effect.

Analysis of fluorescence spectra (Fig. 2b and S2†) clearly allowed us to ascribe the above changes to the occurrence of aggregation processes. Indeed, in solvents like acetone, methanol, chloroform and acetonitrile, main emission bands were quite intense and located at $\sim 385$ and $405 \mathrm{~nm}$. In these solvents the emission is strongly dominated by the monomeric component. Consequently, in these cases, we rule out the possibility of aggregation induced emission, which has been recently observed in amide functionalised NDIs. ${ }^{36}$ However, moving from these solvents to DMF, THF and 1,4-Diox solutions, we detected a loss of the well-resolved spectra and a significant decrease in the fluorescence intensity. Similar changes have been previously reported in literature and have been considered as clear evidences of aggregation processes. ${ }^{37-39}$

In the light of the above results, we performed concentration dependent UV-vis and fluorescence measurements. Concentrations used ranged from $2 \times 10^{-7} \mathrm{M}$ up to $1 \times 10^{-4} \mathrm{M}$. In 

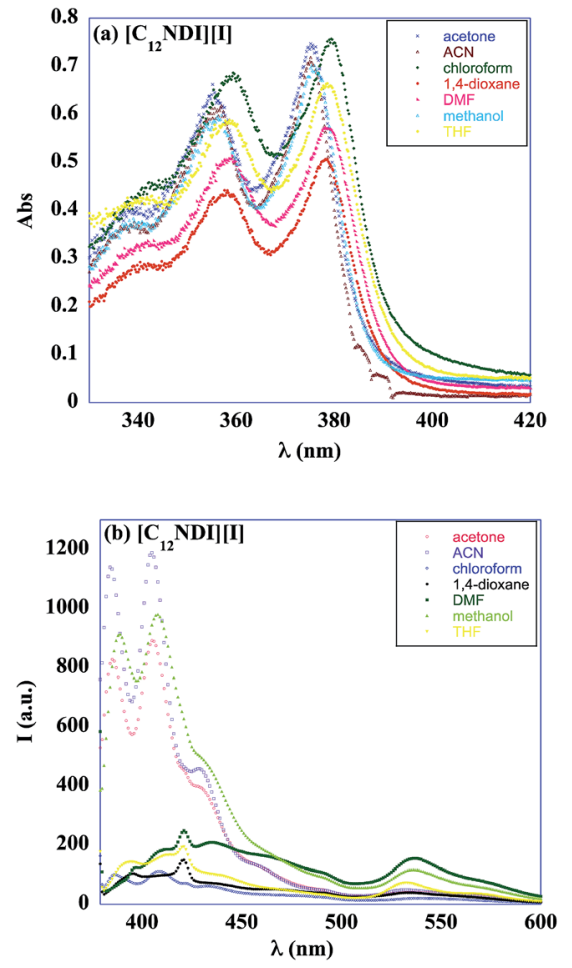

Fig. 2 (a) UV-vis and (b) fluorescence spectra of $\left[\mathrm{C}_{12} \mathrm{NDI}\right][\mathrm{I}]$ at $5 \times$ $10^{-5} \mathrm{M}$ as a function of solvent nature.

particular, to have information about solvent and alkyl chain length effect, with the only exception of $\left[\mathbf{C}_{8} \mathbf{F N D I}\right][\mathbf{I}]$ and [C $\left._{\mathbf{1 2}} \mathbf{F N D I}\right][\mathbf{I}]$, measurements were carried out in THF and DMF. For the last two salts, solubility issues allowed using only DMF. The solvent effect was further investigated using $\left[\mathbf{C}_{\mathbf{1 2}} \mathbf{N D I}\right][\mathbf{I}]$ as model substrate and studying self-assembly process also in 1,4Diox and $\mathrm{CHCl}_{3}$. In Fig. 3 and $\mathrm{S} 3, \dagger \mathrm{UV}$-vis and fluorescence spectra for $\left[\mathbf{C}_{n} \mathbf{N D I}\right][\mathbf{I}]$ are shown as a function of concentration.

UV-vis spectra indicate that intensity of absorption bands gradually increased with salt concentration, without following the Lambert-Beer law. This is better evidenced looking at the trend of molar extinction coefficient $(\varepsilon)$ that drops dramatically as the concentration increased (inset Fig. $3 \mathrm{a}$ and $\mathrm{S} 4 \uparrow$ ). Raising the concentration induced also small but consistent hypsochromic shifts in the main absorption band ranging from 0.9 $\mathrm{nm}$ in DMF to $2 \mathrm{~nm}$ in THF solutions. According to previous reports, ${ }^{\mathbf{6 4 0 - 4 2}}$ the hypsochromic effect is the result of the formation of $H$-type assembly with parallel stacking of chromophores.

As for fluorescence investigation, we detected different trends as a function of the emission wavelength. Indeed, an increase in salt concentration induces a drop in fluorescence intensity $(I)$ in the range 380-500 $\mathrm{nm}$. Moreover, significant changes in the shape of emission band were also observed, like its enlargement and loss of fine structure. Conversely, a raise in intensity of the band located at $\sim 550 \mathrm{~nm}$ was evidenced, further confirming the occurrence of aggregation processes. ${ }^{\mathbf{1 0 4 3}}$ The increase in concentration also induced a blue shift of the main emission band and it was more significant in THF $(\sim 4 \mathrm{~nm})$ than
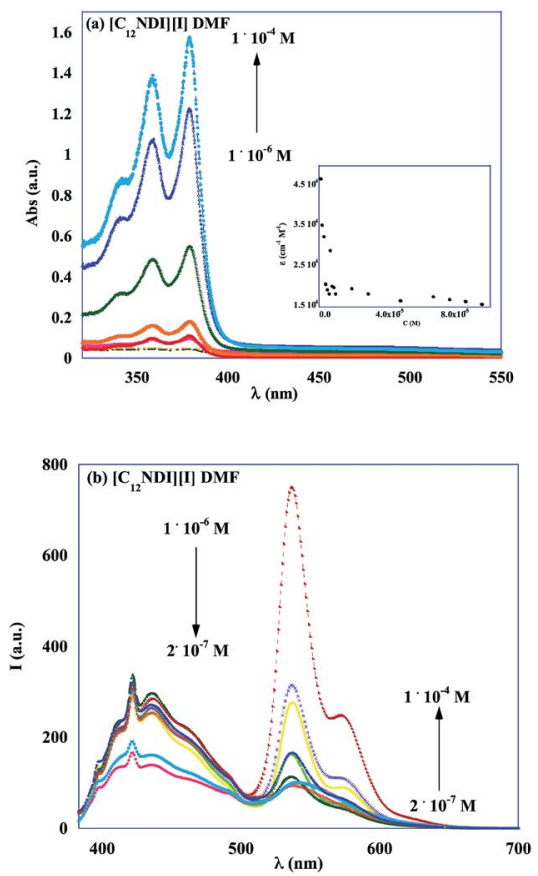

Fig. 3 (a) UV-vis $\left(1 \times 10^{-6} \div 1 \times 10^{-4} \mathrm{M}\right)$ and (b) fluorescence spectra $\left(\lambda_{\mathrm{ex}}=362 \mathrm{~nm}\right)$ of [C $\left.{ }_{12} \mathrm{NDI}\right][\mathrm{I}]\left(2 \times 10^{-7} \div 1 \times 10^{-4} \mathrm{M}\right)$ in DMF solution as a function of concentration.

in DMF solution $(\sim 2 \mathrm{~nm})$. Then, we determined $I / C$ values at $415 \mathrm{~nm}$ for $\left[\mathbf{C}_{\mathbf{8}} \mathbf{N D I}\right][\mathbf{I}]$ in DMF, $\left[\mathbf{C}_{\mathbf{1 0}} \mathbf{N D I}\right][\mathbf{I}]$ in THF and DMF. Moreover, $I / C$ was determined at $533 \mathrm{~nm}$ for $\left[\mathbf{C}_{\mathbf{1 2}} \mathbf{N D I}\right][\mathbf{I}]$ in dioxane, $435 \mathrm{~nm}\left[\mathbf{C}_{\mathbf{1 2}} \mathbf{N D I}\right][\mathbf{I}]$ in $\mathrm{CHCl}_{3}$ and at $422 \mathrm{~nm}$ in all other cases. These values gave as a function of salt concentration a hyperbolic trend, and the determination of inflection point allowed us to calculate the salt concentration corresponding to the onset of aggregation $\left(C_{\mathrm{on}}\right)$. These values are displayed in Fig. 4 and Table S2. $\dagger$

$C_{\text {on }}$ range from $1.0 \times 10^{-6}$ up to $5.5 \times 10^{-6} \mathrm{M}$ in THF and from $1.1 \times 10^{-6}$ up to $3.3 \times 10^{-6} \mathrm{M}$ in DMF solution. In the latter solvent, $C_{\text {on }}$ are generally lower than the ones determined in THF.

Plots in Fig. 4 indicate the presence of two series as a consequence of odd or even number of methylene units in the alkyl chain.

Self-assembly is negatively affected by the presence of fluorinated tails. Indeed, significantly higher $C_{\text {on }}$ were calculated for $\left[\mathbf{C}_{8} \mathbf{F N D I}\right][\mathbf{I}]$ and $\left[\mathbf{C}_{12} \mathbf{F N D I}\right][\mathbf{I}]$ with respect to $\left[\mathbf{C}_{8} \mathbf{N D I}\right][\mathbf{I}]$ and $\left[\mathrm{C}_{12} \mathbf{N D I}\right][\mathbf{I}]$.

As above stated, the solvent effect was analysed for $\left[\mathbf{C}_{12} \mathbf{N D I}\right]$ [I], performing measurements in four solvents. In this case, $C_{\text {on }}$ increases along the series: $C_{\text {on,THF }}<C_{\text {on, DMF }}<C_{\text {on,1,4-Diox }}<$ $C_{\text {on }, \mathrm{CHCl}_{3}}$. The above trend does not fit neither the one of solvent polarity nor viscosity $\left(E_{\mathrm{T}}^{\mathrm{N}}=0.407,0.259,0.207,0.164\right.$ and $\eta=$ $0.79,0.54,0.46$ and $1.18 \mathrm{cP}$ for $\mathrm{DMF}, \mathrm{CHCl}_{3}$, THF and 1,4-Diox, respectively). ${ }^{44}$ Many reports have underlined that factor different from solvent polarity and viscosity, like size and shape of molecules can be crucial in determining self-assembly processes. $^{45,46}$ Consequently, to take in consideration 

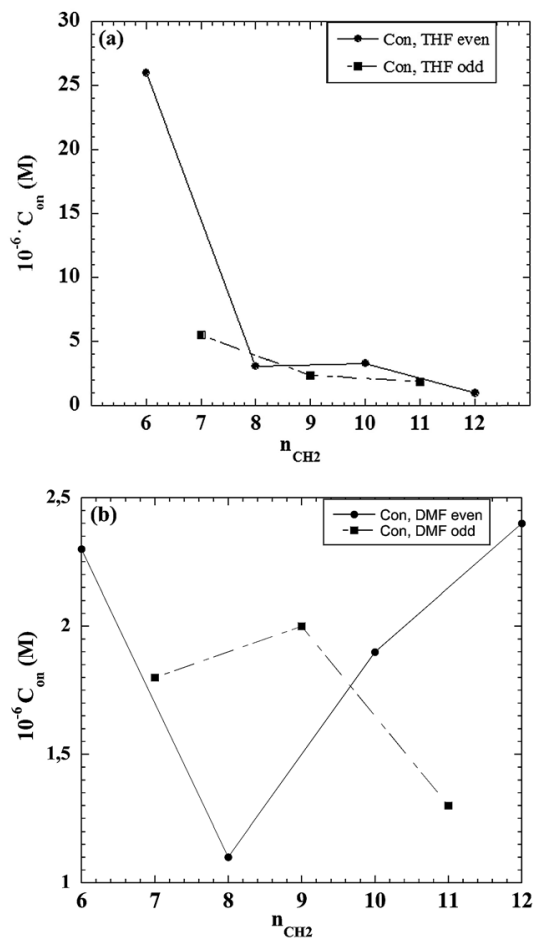

Fig. 4 Plots of $C_{\text {on }}$ as a function of $n_{\mathrm{CH}_{2}}$ (a) in THF and (b) in DMF solution.

geometrical features of solvents, we used DFT optimized geometries and Amber atomic radii, recently determined studying self-assembly processes of some phenyleneethynylene diimidazolium salts. ${ }^{6}$ In particular, the ratio of the smallest to the largest molecular dimension $(m / M)$ gives information about the shape of solvent molecule. In the present case, all solvents used resemble an oblate ellipsoid and with the only exception of DMF, $C_{\text {on }}$ increases with drop in $m / M$ values $(m / M=0.67,0.59$, 0.48 and 0.48 for THF, 1,4-Diox, $\mathrm{CHCl}_{3}$ and DMF respectively). The above result indicates that, shape being the same, selfassembly of [ $\left.\mathbf{C}_{\mathbf{1 2}} \mathbf{N D I}\right][\mathbf{I}]$ is determined by a concomitant action of size and polarity of solvent used. For comparable polarities, the drop in size determines a decrease in the self-assembly ability.

Data collected by fluorescence measurements were further analysed to get quantitative information on the aggregation ability of salts, determining the association constants $\left(K_{\text {ass }}\right)$. To this aim, we calculated the aggregation degree $\left(\alpha_{\text {agg }}\right)$, which is the fraction of molecules present in the aggregates, using the eqn (1)

$$
\alpha_{\mathrm{agg}}=\frac{I_{(\mathrm{C})}-I_{\mathrm{mon}}}{I_{\mathrm{agg}}-I_{\mathrm{mon}}}
$$

where $I_{(\mathrm{C})}$ is the emission intensity at a given concentration, $I_{\text {mon }}$ is the emission intensity detected for the lowest salt concentration and $I_{\text {agg }}$ is the emission intensity detected for the highest salt concentration. $\alpha_{\mathrm{agg}}$ was determined at $415 \mathrm{~nm}$ for

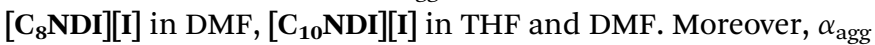
was determined at $533 \mathrm{~nm}$ for [ $\left.\mathbf{C}_{12} \mathbf{N D I}\right][\mathbf{I}]$ in dioxane, $435 \mathrm{~nm}$ $\left[\mathrm{C}_{12} \mathrm{NDI}\right][\mathrm{I}]$ in $\mathrm{CHCl}_{3}$ and at $422 \mathrm{~nm}$ in all other cases. Then, we plotted $\alpha_{\text {agg }}$ as a function of concentration. All plots obtained displayed a sigmoidal trend, where $\alpha_{\text {agg }}$ gradually increased from 0 to 1 as the salt concentration increased (Fig. S5†). According to previous report in literature, ${ }^{47,48}$ such behaviour indicates the occurrence of an isodesmic process of aggregation. In this case, the aggregation is considered as a succession of equilibrium steps in which a monomer is incorporated into the growing stack. In this model of aggregation, the constant is the same irrespective of the length of the stack. To obtain the values of association constant $\left(K_{\text {ass }}\right)$, we fitted this plot by nonlinear least square analysis using eqn (2) based on the isodesmic model: ${ }^{49}$

$$
\alpha_{\text {agg }}=1-\frac{2 K_{\text {ass }} C+1-\left(4 K_{\text {ass }} C+1\right)^{1 / 2}}{\left(2 K_{\text {ass }} C\right)^{2}}
$$

$K_{\text {ass }}$ values as a function of salt and solvent used are reported in Table 1 and displayed in Fig. 5 .

$K_{\text {ass }}$ range from $0.60 \times 10^{6}$ up to $3.00 \times 10^{6} \mathrm{M}^{-1}$ in THF and from $1.40 \times 10^{6}$ up to $4.00 \times 10^{6} \mathrm{M}^{-1}$ in DMF. In THF, the highest stability was detected for $\left[\mathrm{C}_{\mathbf{9}} \mathrm{NDI}\right][\mathbf{I}]$ and $\left[\mathrm{C}_{\mathbf{1 2}} \mathrm{NDI}\right][\mathbf{I}]$, whereas the lowest was observed for $\left[\mathbf{C}_{7} \mathbf{N D I}\right][\mathbf{I}]$. Otherwise, in DMF the lowest stability was detected for $\left[\mathbf{C}_{8} \mathbf{F N D I}\right][\mathbf{I}]$, whereas $\left[\mathrm{C}_{6} \mathbf{N D I}\right][\mathbf{I}]$ gave rise to aggregates having the highest stability.

Trends of $K_{\text {ass }}$ as a function of alkyl chain are different in two solvents. Indeed, in THF it resembles a bell-shaped curve; whereas in DMF $K_{\text {ass }}$ irregularly decreases with a raise in the alkyl chain length (Fig. 5).

The trend obtained in DMF solution indicates that stability of the aggregates is negatively affected by the presence of longer

\begin{tabular}{|c|c|c|c|c|}
\hline Salt & $10^{-6} K_{\mathrm{ass}, \mathrm{THF}}\left(\mathrm{M}^{-1}\right)$ & $10^{-6} K_{\mathrm{ass}, \mathrm{DMF}}\left(\mathrm{M}^{-1}\right)$ & $10^{-6} K_{\mathrm{ass}, \mathrm{CHCl}_{3}}\left(\mathrm{M}^{-1}\right)$ & $10^{-6} K_{\text {ass }, 1,4-\mathrm{Diox}}\left(\mathrm{M}^{-1}\right)$ \\
\hline$\left[\mathrm{C}_{7} \mathrm{NDI}\right][\mathrm{I}]$ & $0.60 \pm 0.06$ & $2.45 \pm 0.10$ & & \\
\hline$\left[\mathrm{C}_{9} \mathrm{NDI}\right][\mathrm{I}]$ & $3.00 \pm 0.10$ & $2.00 \pm 0.10$ & & \\
\hline$\left[\mathrm{C}_{10} \mathrm{NDI}\right][\mathrm{I}]$ & $2.60 \pm 0.10$ & $2.00 \pm 0.10$ & & \\
\hline$\left[\mathrm{C}_{11} \mathrm{NDI}\right][\mathrm{I}]$ & $1.40 \pm 0.10$ & $1.70 \pm 0.10$ & & \\
\hline$\left[\mathrm{C}_{12}\right.$ FNDI $][\mathrm{I}]$ & & $2.20 \pm 0.10$ & & \\
\hline
\end{tabular}

Table 1 Association constants $\left(K_{\text {ass }}\right)$ as a function of different nature of salt and solvent 

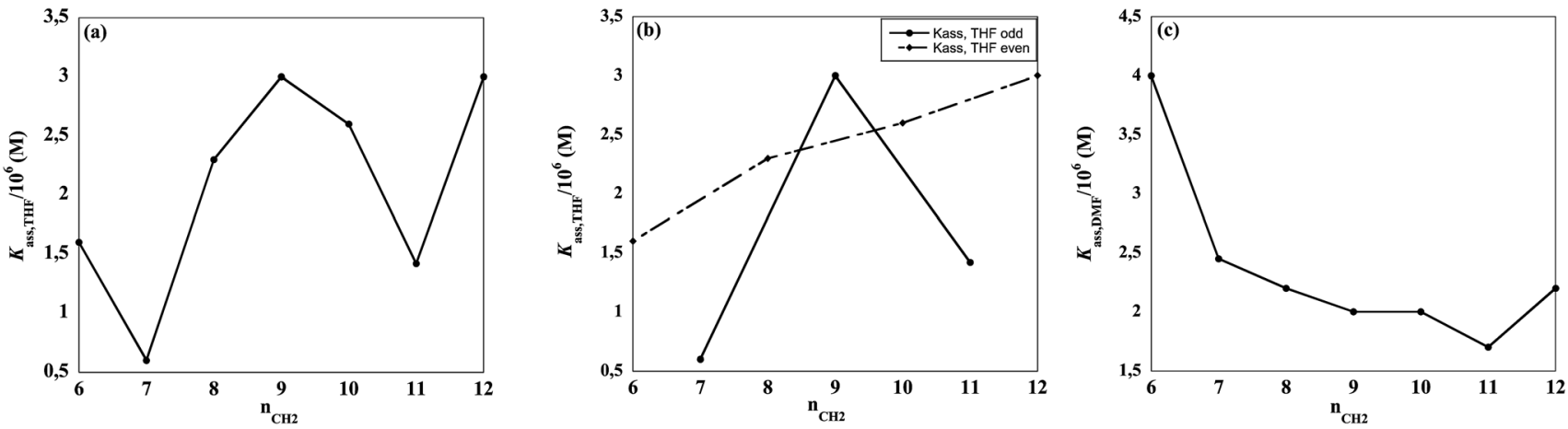

Fig. 5 Plots of $K_{\text {ass }}$ as a function of alkyl chain length determined in: (a) THF; (b) THF for odd or even terms; (c) DMF solution.

alkyl chains. Probably, in such polar solvent, the unfavourable contact with non polar chains induces the partial wrapping of these latter that, interfering with NDI spacer organization, causes a drop in $K_{\text {ass }}$.

On the whole, trend observed in THF is quite complex. However, the above trend can be better understood dissecting salts on the grounds of odd or even number of methylene units in the alkyl chain. For even terms a gradual increase with the alkyl chain length was observed. Differently, for odd terms $\left[\mathbf{C}_{\mathbf{9}} \mathbf{N D I}\right][\mathbf{I}]$ represents the best compromise among stabilizing and destabilizing effects.

The different behaviour of odd and even terms has been already observed in self-assembly processes. It represents one of the main concerns as frequently allows modulating properties and consequently applications of aggregates. Recently, Sànchez et al. have reported data about the effect that odd or even number of methylene units has on the self-assembly of linear bis(benzamides). ${ }^{50}$ Moreover, the presence of odd or even number effect has proven to be crucial in determining the gelling ability in toluene solution of a series of perylenebisimide dimers. ${ }^{51}$

As far as solvent effect is concerned, results obtained perfectly reassert the considerations about $C_{\text {on }}$. Indeed, size of solvent molecules determines trend of $K_{\text {ass }}$, as accounted for by its parallel decrease with $m / M$ ratio $\left(K_{\mathrm{ass}}\right.$ : THF $>1,4$-Diox $>$ $\mathrm{CHCl}_{3}$ ).

By contrast, the effect of the fluorinated tail resulted different depending on the alkyl chain length. Indeed, aggregates of lower stability were formed by $\left[\mathbf{C}_{\mathbf{8}} \mathbf{F N D I}\right][\mathbf{I}]$ with respect to the ones formed by $\left[\mathbf{C}_{\mathbf{8}} \mathbf{N D I}\right][\mathbf{I}]$. However, no significant differences were observed as far as corresponding dodecyl derivatives were compared.

As above stated, spectroscopic shifts indicates the occurrence in our systems of $\mathrm{H}$-aggregates that could be stabilized by $\pi-\pi$, van der Waals and hydrogen bond formation. To estimate the relevance of hydrogen bonding, we used a protic solvent $(\mathrm{MeOH})$ that did not support aggregation. To this aim, we performed a fluorescence investigation, at fixed salt concentration $\left(5 \times 10^{-5} \mathrm{M}\right)$, in some $\mathrm{THF} / \mathrm{MeOH}$ and $\mathrm{DMF} / \mathrm{MeOH}$ mixtures having variable composition. Fluorescence spectra collected for $\left[\mathbf{C}_{\mathbf{1 2}} \mathbf{N D I}\right][\mathbf{I}]$ are reported in Fig. 6.
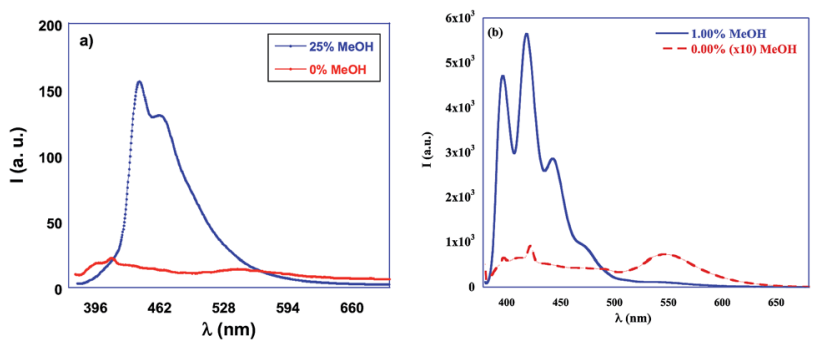

Fig. 6 Fluorescence spectra of $\left[\mathrm{C}_{12} \mathrm{NDI}\right][\mathrm{I}]$ at $5 \times 10^{-5} \mathrm{M}$ : (a) in THF/ $\mathrm{MeOH}$ and (b) $\mathrm{DMF} / \mathrm{MeOH}$ binary mixtures as a function of $\mathrm{MeOH}$ percentage $\left(\lambda_{\mathrm{ex}}=362 \mathrm{~nm}\right)$.

We obtained almost complete conversion of aggregates into monomeric species in the presence of 1 and $25 \%$ of $\mathrm{MeOH}$ for $\mathrm{MeOH} / \mathrm{DMF}$ and $\mathrm{MeOH} / \mathrm{THF}$ binary mixtures respectively. This result perfectly agrees with the one reported by Ghosh et al. about self-assembly of some bis-(trialkoxybenzamide)-functionalized NDI chromophores. ${ }^{41}$

\section{Temperature-dependent measurements}

Self-assembly processes were also studied as a function of temperature, performing UV-vis measurements and using salts solution having a fixed concentration $\left(5 \times 10^{-5} \mathrm{M}\right)$. Investigation was carried out in all cases in which we had evidences of aggregation processes.

For all salts in THF and for $\left[\mathbf{C}_{\mathbf{1 2}} \mathbf{N D I}\right][\mathbf{I}]$ in DMF and $\mathrm{CHCl}_{3}$ solution, we detected significant spectral changes with the temperature and, at the highest value, we observed the presence of the fully monomeric species. This allowed us to analyse the effect of the alkyl chain length and solvent nature on thermodynamic parameters. In all the other cases, we obtained only a partial disruption of aggregates. The above evidences suggest a considerable thermal stability of the aggregates, according to previous reports in literature. ${ }^{52} \mathrm{UV}$-vis spectra as a function of temperature are reported in Fig. 7 and S6. $\dagger$

In the cases in which we observed the complete melting of the aggregate, we determined the fractions of aggregates molecules $\left(\alpha_{\text {agg }}\right)$ and we plotted them as a function of temperature (Fig. $7 \mathrm{~b}$ and $\mathrm{S} 7 \dagger$ ). Plots obtained were consistent with an 

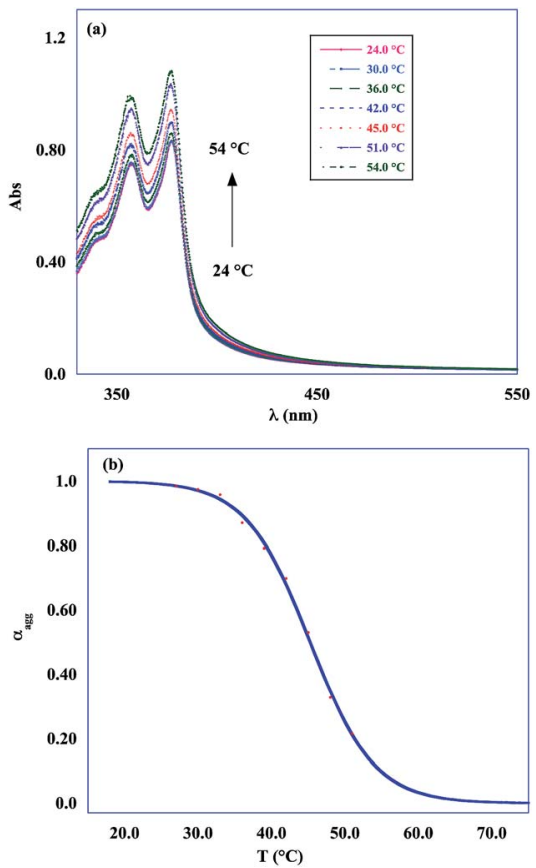

Fig. 7 (a) UV-vis spectra as a function of temperature for [ $\mathrm{C}_{12} \mathrm{NDI}$ [I] (5 $\left.\times 10^{-5} \mathrm{M}\right)$ in THF; (b) plot of $\alpha_{\mathrm{gg}}$ as a function of temperature $(\lambda=374$ $\mathrm{nm})$.

isodesmic aggregation pathway and could be fitted using eqn (3) based on the isodesmic model derived by Meijer et al. ${ }^{\mathbf{5 3}}$

$$
\alpha_{\mathrm{agg}}=1-\frac{1}{1+\exp \left(\frac{T-T_{\mathrm{m}, \mathrm{agg}}}{T^{*}}\right)}
$$

where $T_{\mathrm{m} \text {,agg }}$ is the melting temperature of the aggregate, i.e. the temperature at which at which $\alpha_{\text {agg }}$ is 0.5 , while $T^{*}$ is a characteristic temperature related to the slope of the curve at $T_{\mathrm{m} \text {,agg. }}$. To have further information, we determined association constant values at each temperature from the corresponding degree of aggregation, following the procedure reported by Meijer et al. (details of calculation method are reported in ESI $\dagger$ ). Then, we applied the van't Hoff treatment, obtaining enthalpy and entropy variations corresponding to aggregation processes

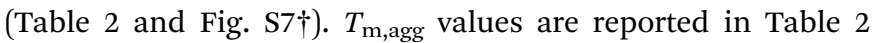
together with thermodynamic parameters.

Melting temperatures in THF range from 37 up to $45{ }^{\circ} \mathrm{C}$, indicating only a modest effect of the alkyl chain length. Once again, trend of $T_{\mathrm{m} \text {,agg }}$ as a function of the alkyl chain length can be rationalized only dissecting salts used on the grounds of odd or even number of methylene units. Indeed, for even terms, $T_{\mathrm{m} \text {,agg }}$ has the lowest values for $\left[\mathbf{C}_{\mathbf{8}} \mathbf{N D I}\right][\mathbf{I}]$. Then, it regularly increases with the alkyl chain length. Differently, for odd terms, melting temperature decreases with the increase in the alkyl chain length (Fig. 8).

Analysis of $\Delta H$ and $\Delta S$ values shows that aggregation of salts is enthalpy driven. As far as alkyl chain length is concerned, from a thermodynamic point of view, $\left[\mathbf{C}_{\mathbf{9}} \mathbf{N D I}\right][\mathbf{I}]$ represents the "inversion point" (Fig. S8†). Indeed, in the range C6-C9, the enthalpy becomes gradually more negative with the increase in
Table 2 Melting temperatures $\left(T_{\mathrm{m} \text {,agg }}\right)$, enthalpy $(\Delta H)$ and entropy $(\Delta S)$ variations corresponding to melting processes of aggregates as a function of salt and solvent

\begin{tabular}{llll}
\hline Salt/solvent & $T_{\mathrm{m}, \text { agg }{ }^{a}\left({ }^{\circ} \mathrm{C}\right)}$ & $\Delta H\left(\mathrm{~kJ} \mathrm{~mol}^{-1}\right)$ & $\Delta S\left(\mathrm{~J} \mathrm{~K}^{-1} \mathrm{~mol}^{-1}\right)$ \\
\hline$\left[\mathbf{C}_{\mathbf{6}} \mathbf{N D I}\right][\mathbf{I}] / \mathrm{THF}$ & 43 & $-140 \pm 1$ & $-370 \pm 2$ \\
{$\left[\mathbf{C}_{7} \mathbf{N D I}\right][\mathbf{I}] / \mathrm{THF}$} & 45 & $-195 \pm 2$ & $-540 \pm 6$ \\
{$\left[\mathbf{C}_{\mathbf{8}} \mathbf{N D I}\right][\mathbf{I}] / \mathrm{THF}$} & 37 & $-240 \pm 1$ & $-690 \pm 3$ \\
{$\left[\mathbf{C}_{\mathbf{9}} \mathbf{N D I}\right][\mathbf{I}] / \mathrm{THF}$} & 43 & $-350 \pm 5$ & $-1020 \pm 15$ \\
{$\left[\mathbf{C}_{\mathbf{1 0}} \mathbf{N D I}\right][\mathbf{I}] / \mathrm{THF}$} & 41 & $-170 \pm 1$ & $-460 \pm 4$ \\
{$\left[\mathbf{C}_{\mathbf{1 1}} \mathbf{N D I}\right][\mathbf{I}] / \mathrm{THF}$} & 41 & $-130 \pm 1$ & $-330 \pm 2$ \\
{$\left[\mathbf{C}_{\mathbf{1 2}} \mathbf{N D I}\right][\mathbf{I}] / \mathrm{THF}$} & 45 & $-200 \pm 2$ & $-550 \pm 7$ \\
{$\left[\mathbf{C}_{\mathbf{1 2}} \mathbf{N D I}\right][\mathbf{I}] / \mathrm{CHCl}$} & 45 & $-210 \pm 2$ & $-580 \pm 6$ \\
{$\left[\mathbf{C}_{\mathbf{1 2}} \mathbf{N D I}\right][\mathbf{I}] / \mathrm{DMF}$} & 77 & $-40 \pm 1$ & $-30 \pm 1$
\end{tabular}

${ }^{a}$ In all cases standard deviations were lower than $1 \%$.
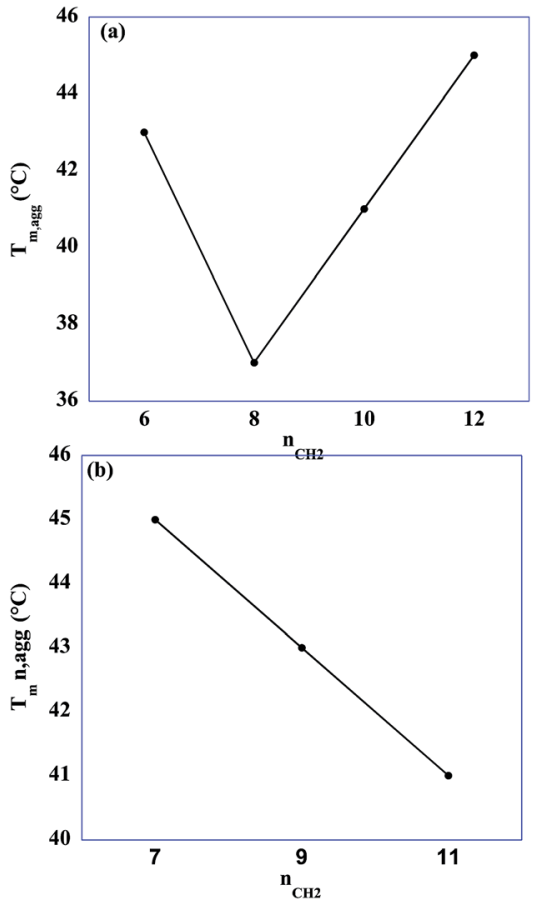

Fig. 8 Trends of $T_{\text {m,agg }}$ values as a function of: (a) even and (b) odd number of methylene units in the alkyl chain.

the alkyl chain length. Differently, for salts with longer alkyl chains a gradual gain in entropy can be evidenced, probably as a consequence of the more difficult organization of the side tail that induces a higher disorder degree in the monomers.

As for solvent effect in the case of $\left[\mathbf{C}_{\mathbf{1 2}} \mathbf{N D I}\right][\mathbf{I}]$, comparable $T_{\text {m,agg }}$ were obtained in THF and $\mathrm{CHCl}_{3}$, whereas a significantly higher value was calculated in DMF. This can be ascribed to more positive enthalpy variation and can be the result of the unfavourable polar/apolar contact between solvent and side chain that maximizes van der Waals interactions among monomers and positively contributes to aggregate stability.

Temperature dependent measurements were also carried out using ${ }^{1} \mathrm{H}$ NMR to identify the protons mainly involved in the supramolecular interactions. Investigation was performed on 
$\left[\mathrm{C}_{6} \mathrm{NDI}\right][\mathbf{I}],\left[\mathrm{C}_{12} \mathrm{NDI}\right][\mathbf{I}],\left[\mathrm{C}_{8} \mathrm{FNDI}\right][\mathbf{I}]$ and $\left[\mathrm{C}_{12} \mathrm{FNDI}\right][\mathbf{I}]$, in DMSO$\left[\mathrm{d}_{6}\right]$ solution at a fixed concentration $\left(7.5 \times 10^{-3} \mathrm{M}\right)$.

As for $\left[\mathbf{C}_{6} \mathbf{N D I}\right][\mathbf{I}]$ and $\left[\mathbf{C}_{12} \mathbf{N D I}\right][\mathbf{I}]$, at $27^{\circ} \mathrm{C}$, we observed the enlargement and loss of multiplicity for signals corresponding to protons on the alkyl tail (Fig. S9†). Furthermore, we also noticed the presence of signals in the range $7.30-7.70 \mathrm{ppm}$ that could not be easily ascribed to protons of dications. Temperature increase to $85{ }^{\circ} \mathrm{C}$ induced an improvement in the signals multiplicity, without affecting chemical shift.

To better identify the origin of the above signals, we recorded ${ }^{1} \mathrm{H}$ NMR spectrum of $\left[\mathrm{C}_{12} \mathrm{NDI}\right][\mathbf{I}]$ in $\mathrm{CD}_{2} \mathrm{Cl}_{2}$, a solvent that did not support aggregation. The absence of the above signals induced us to hypothesize the occurrence of self-assembly processes in DMSO- $\left[\mathrm{d}_{6}\right]$ and to ascribe them to aggregated species. Moreover, the absence of chemical shift variation with temperature could be the evidence of significant stability of the aggregates, perfectly recalling the situation observed in DMF solution for the same salt using UV-vis measurements.

As far as $\left[\mathbf{C}_{8} \mathbf{F N D I}\right][\mathbf{I}]$ and $\left[\mathbf{C}_{12} \mathbf{F N D I}\right][\mathbf{I}]$ are concerned, NMR investigation confirmed the presence of aggregates in the used experimental conditions at $27{ }^{\circ} \mathrm{C}$ (Fig. S10 $\dagger$ ). In these cases, signals at 8.86 and in the range $7.71-7.50 \mathrm{ppm}$ were observed. Temperature increase induced a downfield shift of the above signals and it was more significant for $\left[\mathbf{C}_{\mathbf{1 2}} \mathbf{F N D I}\right][\mathbf{I}]$ with respect

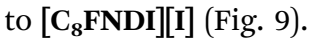
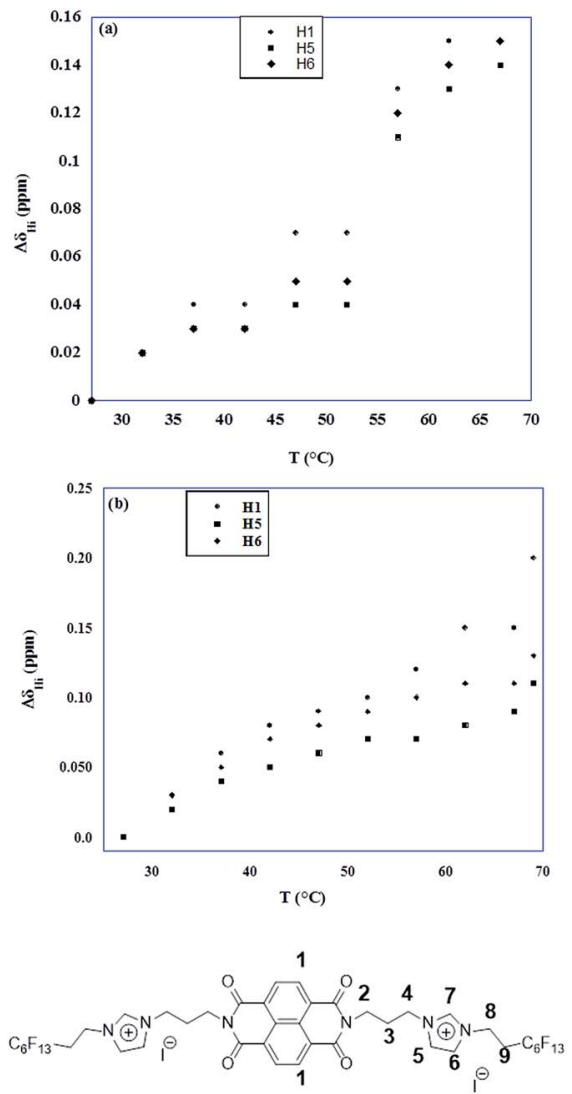

Fig. 9 Trend of $\Delta \delta_{\mathrm{Hi}}$ (ppm) for (a) [C ${ }_{8}$ FNDI] [I] and (b) $\left[\mathrm{C}_{12}\right.$ FNDI][I] as a function of temperature in DMSO- $\left[\mathrm{d}_{6}\right]$ solution $\left(7.5 \times 10^{-3} \mathrm{M}\right)$.
The above result accounts for a lower thermal stability of aggregates formed by salts bearing fluorinated tails with respect to corresponding hydrogenated terms. Moreover, it allows identifying protons of naphthalene core, together with $\mathrm{H} 5$ and H6 (as labelled in Fig. 9) of imidazolium ion as the most affected by supramolecular interactions, further supporting the hypothesis of $\mathrm{H}$-aggregates formation in which chromophores are arranged face to face.

Properties of aggregates were also investigated in solid state using fluorescence spectroscopy and scanning electron microscopy. In both cases, we analysed thin films obtained from casting of solutions at a fixed concentration $\left(5 \times 10^{-5} \mathrm{M}\right)$.

\section{Solid state fluorescence measurements}

As far as fluorescence in solid state is concerned, we were interested in analysing both solvent and alkyl chain length effect. Consequently, spectra were recorded on thin films obtained from THF solution of all salts and from $\mathrm{CHCl}_{3}, \mathrm{DMF}$ and 1,4-dioxane solution of [ $\left.\mathrm{C}_{\mathbf{1 2}} \mathrm{NDI}\right][\mathbf{I}]$.

In all cases we detected intense fluorescence signals with broad emission bands in the solid state. To have a comparison with spectra collected in solution and identify the position of main bands, we performed deconvolution of solid state emission bands. Superimposed normalized spectra recorded in solution and in solid state are displayed in Fig. 10 and S11. $\dagger$

After deconvolution, analysis of solid state spectra indicates that $\lambda_{\max }$ of emission band located at $\sim 360 \mathrm{~nm}$ corresponds to emission band collected in solution and located in the range $410-420 \mathrm{~nm}$. In all cases, on going from solution to solid state an hypsochromic shift was observed and according to previous report this should indicate the occurrence of $\mathrm{H}$-aggregation. ${ }^{54}$

The largest and the lowest shifts $\left(\Delta \lambda_{\max }\right)$ were equal to 44 and $18 \mathrm{~nm}$ and they were detected for thin film obtained for [ $\left.\mathrm{C}_{12} \mathrm{NDI}\right][\mathbf{I}]$ from casting of DMF and 1,4-dioxane solutions and for $\left[\mathrm{C}_{9} \mathrm{NDI}\right][\mathbf{I}]$ from casting of THF solution, respectively $\left(\lambda_{\max }\right.$ values for solution and solid state spectra are reported in Table S3†).

With the only exception of $\left[\mathrm{C}_{9} \mathbf{N D I}\right][\mathbf{I}], \Delta \lambda_{\max }$ were not affected by alkyl chain length. On the other hand, shifts

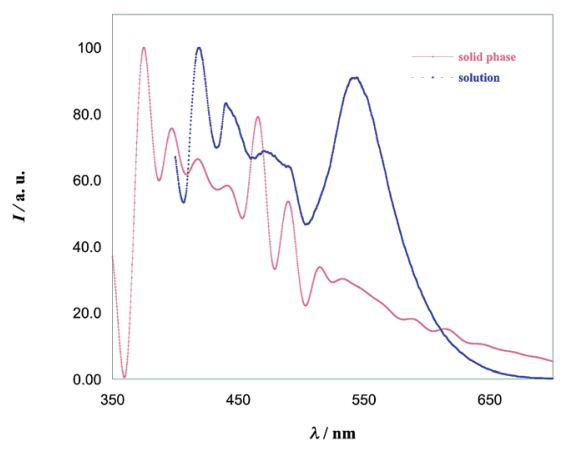

Fig. 10 Fluorescence spectra of [ $\left.\mathrm{C}_{12} \mathrm{NDI}\right][\mathrm{I}]$ in DMF solution $\left(5 \times 10^{-5}\right.$ M) and thin film obtained from casting of DMF solution ( $\lambda_{\mathrm{ex}}=390 \mathrm{~nm}$ and $273 \mathrm{~nm}$ respectively). 
detected for $\left[\mathbf{C}_{\mathbf{1 2}} \mathbf{N D I}\right][\mathbf{I}]$ films were barely affected by the nature of solvent.

\section{SEM investigation}

Morphology of some selected aggregates was investigated performing SEM measurements. In particular, we took in consideration the effect of the alkyl chain length, solvent polarity and the presence of fluorinated tails. To pursue these goals, SEM measurements were carried out on the thin films obtained from casting on aluminium stubs of $\left[\mathbf{C}_{6} \mathbf{N D I}\right][\mathbf{I}]$ THF solution, and $\left[\mathrm{C}_{6} \mathrm{NDI}\right][\mathbf{I}],\left[\mathrm{C}_{12} \mathrm{NDI}\right][\mathrm{I}]$ and $\left[\mathrm{C}_{\mathbf{1 2}} \mathrm{FNDI}\right][\mathrm{I}]$ DMF solutions. SEM images are reported in Fig. 11 and $\mathrm{S} 12 . \dagger$

As far as solvent effect is concerned, images collected for $\left[\mathbf{C}_{6} \mathbf{N D I}\right][\mathbf{I}]$ in THF and DMF show that increase in solvent polarity induces an increase in the thickness of texture characterizing materials obtained (Fig. 11a and b). In both cases, they are featured by the presence of disk like aggregates. Diameter of above aggregates range from 260 up to $1560 \mathrm{~nm}$ for materials obtained from DMF solution and, from 460 up to 1560 $\mathrm{nm}$ for the ones obtained from THF solution (Fig. S12a and $\mathrm{b} \dagger$ ). However, in the first case a continuous film was obtained; whereas as for film deriving from THF solution, disk-like aggregates were arranged in a sponge-like three-dimensional structure (Fig. 11).

The increase in the alkyl chain length, on going from [ $\left.\mathrm{C}_{6} \mathbf{N D I}\right]$ $[\mathbf{I}]$ to $\left[\mathbf{C}_{\mathbf{1 2}} \mathbf{N D I}\right][\mathbf{I}]$, induces a change in the shape of aggregates. Indeed, comparison between SEM images collected from

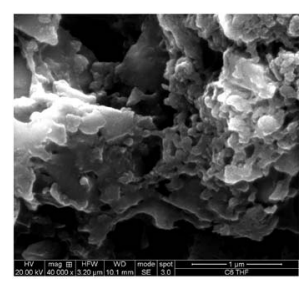

(a)

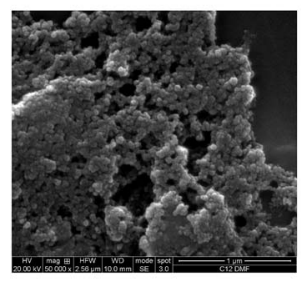

(c)

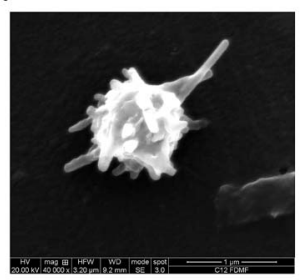

(e)

Fig. 11 SEM images collected at $5 \times 10^{-5} \mathrm{M}$ from casting of (a) [C $\left.{ }_{6} \mathrm{NDI}\right]$ [I] in THF; (b) [C ${ }_{6} \mathrm{NDI}$ [I] in DMF; (c) $\left[\mathrm{C}_{12} \mathrm{NDI}\right][\mathrm{I}]$ in DMF; (d) and (e) $\left[\mathrm{C}_{12} \mathrm{FNDI}\right][\mathrm{l}]$ in DMF.

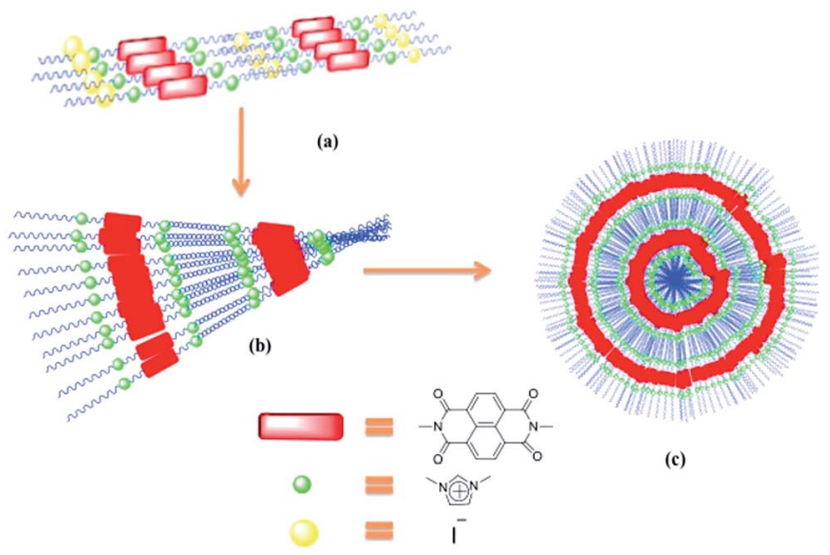

Fig. 12 Suggested schematic model of aggregation. (a) Front view of an oligomer with anions included. (b) Side view of a growing stack. (c) Representation of the final aggregates. Anions are omitted in (b) and (c) for the sake of clarity.

casting of DMF solutions evidences the transition from disk like to spherical aggregates (Fig. S12b and c $\dagger$ ). Furthermore, in the latter case, they are less extended as accounted for by their main size that ranges from 365 up to $848 \mathrm{~nm}$.

Finally, on going from $\left[\mathrm{C}_{\mathbf{1 2}} \mathbf{N D I}\right][\mathbf{I}]$ to $\left[\mathrm{C}_{\mathbf{1 2}} \mathbf{F N D I}\right][\mathbf{I}]$, no significant changes in morphology were detected. The presence of fluorinated tail gave rise only to formation of less porous aggregates (Fig. S12d †).

\section{Conclusions}

It is well known that properties of self-assembled systems can be tailored to their applications by small changes on the structure of tectons. So, combining the properties of NDI chromophore and imidazolium ion, we have obtained a new series of fluorescent diimidazolium salts differing for the alkyl chain length and for the presence of hydrogenated or fluorinated tails. Our main goal was understanding the effects exerted by different features of alkyl chain borne on the imidazolium ions on the self-assembly ability of the salts.

The presence of chains having a different number of methylene units gave rise to different behaviours. Indeed, stability of the aggregates is the result of a fine balance between the positive contribution of van der Waals interactions and the negative one deriving from conformational factors and entanglement of alkyl chain.

All these salts give rise to the formation of $\mathrm{H}$-aggregates in THF and DMF solution, as well as in the solid state. In these aggregates, chromophore are stacked face to face and their stability, other than van der Waals interactions, is mainly determined by $\pi-\pi$ stacking and hydrogen bond between iodide and the protons on imidazolium ions. This latter motif is well known for imidazolium salts and it is recognized as the main contribution that gives rise to the formation of their supramolecular polymers. ${ }^{55}$

Trend of properties of organic salts, as well as the ones of aggregates they are able to form, can be rationalized only 
dissecting them in two series on the grounds of odd or even number of methylene units in the alkyl chain. On the other hand, the comparison between substrates bearing hydrogenated or fluorinated alkyl chain demonstrate that fluorination increase the strength of interactions in the solid state, as accounted for by the increase in $T_{\mathrm{m}}$ values. By contrast, a significant decrease in the stability of the aggregates formed in solution was detected only for octyl derivative.

SEM investigation allows evidencing the presence in the thin films of spherical or disk-like aggregates, completing the picture about the studied system and allowing suggesting the schematic model of aggregation reported below (Fig. 12).

\section{Experimental}

\section{Material}

1,4,5,8-Naphthalenetetracarboxylic dianhydride, 1-(3-aminopropyl)imidazole, 1-iodohexane, 1-iodoheptane, 1-iodooctane, 1-iodononane, 1-iododecane, 1-iodoundecane, 1-iodododecane, 1,1,2,2-tetrahydroperfluorooctyliodide, 1,1,2,2-tetrahydroperfluorododecyliodide were purchased and used without further purification.

$N, N$-Dimethylformamide, tetrahydrofuran, acetonitrile and chloroform were purchased and used without further purification. Dichloromethane, 1,4-dioxane, methanol and acetone were distilled before use.

\section{High resolution mass spectrometry}

High resolution mass spectra were obtained on a Q-TOF mass spectrometer equipped with a dual AJS ESI ion source.

\section{Spectroscopic measurements at variable concentration and temperature}

All the samples were prepared by dilution of stock solutions in dichloromethane $\left(1 \times 10^{-4} \mathrm{M}, 1 \times 10^{-5} \mathrm{M}, 1 \times 10^{-6} \mathrm{M}\right)$. The proper amount of these solutions was put into a vial. The solvent was removed under vacuum, and the solid obtained was dissolved in $2 \mathrm{~mL}$ of the desired solvent. To favour dissolution, each sample was sonicated for 2 minutes. In general the concentration ranged from $2 \times 10^{-7} \mathrm{M}$ up to $1 \times 10^{-4} \mathrm{M}$. The UV-vis measurements were performed using a spectrophotometer equipped with a Peltier temperature controller. UV-vis spectra were recorded using quartz cuvette with a light path of $1 \mathrm{~cm}$, in the wavelength range between $300 \mathrm{~nm}$ and $750 \mathrm{~nm}$. Before recording spectra, each solution was equilibrated at $25{ }^{\circ} \mathrm{C}$.

Measurements at variable temperature were carried out on 5 $\times 10^{-5} \mathrm{M}$ solutions. The temperature range and ramp were chosen in dependence of the solvent (in the case of THF from 20 ${ }^{\circ} \mathrm{C}$ to $55{ }^{\circ} \mathrm{C}$ with a temperature increase of $3{ }^{\circ} \mathrm{C}$; in the case of DMF from $20{ }^{\circ} \mathrm{C}$ to $100{ }^{\circ} \mathrm{C}$ with a temperature increase of $5{ }^{\circ} \mathrm{C}$ ).

\section{Fluorescence measurements}

Fluorescence measurements were performed at $25{ }^{\circ} \mathrm{C}$ on a spectrofluorophotometer equipped with temperature controller. Measurements were conducted 24 hours after the preparation of the solutions. Spectra were recorded from 377 $\mathrm{nm}$ to $700 \mathrm{~nm}$, using quartz cuvette with a light path of $1 \mathrm{~cm}$ both in excitation and in emission. Solid-state fluorescence spectra were recorded from casting of organic salt solutions (5 $\left.\times 10^{-5} \mathrm{M}\right)$ onto quartz plates. Spectra were recorded using a high-pass filter with $\lambda$ equal to $375 \mathrm{~nm}$. To ensure a meaningful comparison between solid- and solution phase spectra, the excitation spectra were recorded for each sample. Then the emission spectra were obtained by exciting the samples at those wavelengths.

\section{Differential scanning calorimetry}

DSC measurements were carried out using a Q20 instrument calibrated using indium as standard. Samples were weighed in aluminium pans and hermetically sealed. Heating and cooling rates were $20^{\circ} \mathrm{C} \mathrm{min}^{-1}$. The maximum heating temperature was varied in dependence of the sample; the minimum cooling temperature was set at $-5{ }^{\circ} \mathrm{C}$ under nitrogen atmosphere. For each sample two heat-cool cycles were performed.

\section{Scanning electron microscopy}

SEM images were recorded by using FEI Quanta 200 instrument with $20 \mathrm{kV}$ operating voltage. $10 \mu \mathrm{L}$ of the solution $\left(5 \times 10^{-5} \mathrm{M}\right)$ was placed on the aluminium stub and the solvent was evaporated under vacuum. The superficial layer was shielded by gold.

\section{NMR measurements}

${ }^{1} \mathrm{H}$ NMR, ${ }^{13} \mathrm{C}$ NMR spectra were recorded using Bruker AV-300 and AV-400 nuclear magnetic resonance spectrometers. Chemical shifts were reported relative to $\mathrm{SiMe}_{4} \cdot{ }^{1} \mathrm{H}$ NMR spectra at variable temperature were recorded using a $300 \mathrm{MHz}$ nuclear magnetic resonance spectrometer. Temperature ranges were changed as a function as of the alkyl chain nature $\left(27-85^{\circ} \mathrm{C}\right.$ for the hydrogenated and $27-70{ }^{\circ} \mathrm{C}$ for fluorinated alkyl chain, respectively).

\section{Acknowledgements}

We thank MIUR (FIRB 2010RBFR10BF5V) for financial support.

\section{References}

1 L. F. Lindoy and I. M. Atkinson, in Self Assembly in Supramolecular Systems, ed. J. F. Stoddart, L. F. Lindoy and I. M. Atkinson, The Royal Society of Chemistry, 2000, pp. 1-6.

2 C. Chen, K. Liu, J. Li and X. Yan, Adv. Colloid Interface Sci., 2015, 225, 177-193.

3 H. E. Katz, A. J. Lovinger, J. Johnson, C. Kloc, T. Siegrist, W. Li, Y. Y. Lin and A. Dodabalapur, Nature, 2000, 404, 478-481.

4 G. M. Whitesides and B. Grzybowski, Science, 2002, 295, 2418-2421.

5 X. Yan, H. Wang, C. E. Hauke, T. R. Cook, M. Wang, M. L. Saha, Z. Zhou, M. Zhang, X. Li, F. Huang and P. J. Stang, J. Am. Chem. Soc., 2015, 137, 15276-15286. 
6 P. Vitale, F. D'Anna, F. Ferrante, C. Rizzo and R. Noto, Phys. Chem. Chem. Phys., 2015, 17, 26903-26917.

7 J. F. Hulvat, M. Sofos, K. Tajima and S. I. Stupp, J. Am. Chem. Soc., 2005, 127, 366-372.

8 P. Leclère, M. Surin, P. Viville, R. Lazzaroni, A. F. M. Kilbinger, O. Henze, W. J. Feast, M. Cavallini, F. Biscarini, A. P. H. J. Schenning and E. W. Meijer, Chem. Mater., 2004, 16, 4452-4466.

9 C. A. Hunter and J. K. M. Sanders, J. Am. Chem. Soc., 1990, 112, 5525-5534.

10 F. Wurthner, Z. Chen, V. Dehm and V. Stepanenko, Chem. Commun., 2006, 1188-1190.

11 A. Kohler, Nat. Mater., 2012, 11, 836-837.

12 S. V. Bhosale, C. H. Jani and S. J. Langford, Chem. Soc. Rev., 2008, 37, 331-342.

13 C. R. Newman, C. D. Frisbie, D. A. da Silva Filho, J.-L. Brédas, P. C. Ewbank and K. R. Mann, Chem. Mater., 2004, 16, 44364451.

14 Z. Chen, A. Lohr, C. R. Saha-Moller and F. Wurthner, Chem. Soc. Rev., 2009, 38, 564-584.

15 Z. Gao and N. Tansil, Anal. Chim. Acta, 2009, 636, 77-82.

16 M. Nakamura, K. Tsuto, A. Jomura, T. Takada and K. Yamana, Chem.-Eur. J., 2015, 21, 11788-11792.

17 S. Bhosale, A. L. Sisson, P. Talukdar, A. Fürstenberg, N. Banerji, E. Vauthey, G. Bollot, J. Mareda, C. Röger, F. Würthner, N. Sakai and S. Matile, Science, 2006, 313, 8486.

18 Y.-L. Wu, K. E. Brown, D. M. Gardner, S. M. Dyar and M. R. Wasielewski, J. Am. Chem. Soc., 2015, 137, 3981-3990.

19 K. Liu, Y. Yao, Y. Liu, C. Wang, Z. Li and X. Zhang, Langmuir, 2012, 28, 10697-10702.

20 K. Liu, Y. Yao, C. Wang, Y. Liu, Z. Li and X. Zhang, Chem.Eur. J., 2012, 18, 8622-8628.

21 F. D'Anna and R. Noto, Eur. J. Org. Chem., 2014, 2014, 42014223.

22 T. S. Jo, J. J. Koh, H. Han and P. K. Bhowmik, Mater. Chem. Phys., 2013, 139, 901-910.

23 X. Li, D. W. Bruce and J. N. M. Shreeve, J. Mater. Chem., 2009, 19, 8232-8238.

24 C. J. Zhong, W. S. V. Kwan and L. L. Miller, Chem. Mater., 1992, 4, 1423-1428.

25 F. D'Anna, S. Marullo, G. Lazzara, P. Vitale and R. Noto, Chem.-Eur. J., 2015, 21, 14780-14790.

26 T. Lei, J.-Y. Wang and J. Pei, Chem. Mater., 2014, 26, 594-603.

27 S. Thankaraj Salammal, S. Dai, U. Pietsch, S. Grigorian, N. Koenen, U. Scherf, N. Kayunkid and M. Brinkmann, Eur. Polym. J., 2015, 67, 199-212.

28 A. Abate, A. Petrozza, G. Cavallo, G. Lanzani, F. Matteucci, D. W. Bruce, N. Houbenov, P. Metrangolo and G. Resnati, J. Mater. Chem., 2013, 1, 6572-6578.

29 S.-G. Park and T. Mori, Ferroelectrics, 2015, 478, 170-175.

30 B. Xin and J. Hao, RSC Adv., 2012, 2, 5141-5146.

31 N. C. Tansil, H. Xie, F. Xie and Z. Gao, Anal. Chem., 2005, 77, 126-134.
32 M. K. Mishra, S. Varughese, U. Ramamurty and G. R. Desiraju, J. Am. Chem. Soc., 2013, 135, 8121-8124.

33 G. Adamova, J. N. Canongia Lopes, L. P. N. Rebelo, L. M. N. B. Santos, K. R. Seddon and K. Shimizu, Phys. Chem. Chem. Phys., 2014, 16, 4033-4038.

34 Z. Zeng, B. S. Phillips, J.-C. Xiao and J. N. M. Shreeve, Chem. Mater., 2008, 20, 2719-2726.

35 N. S. M. Vieira, P. M. Reis, K. Shimizu, O. A. Cortes, I. M. Marrucho, J. M. M. Araujo, J. M. S. S. Esperanca, J. N. C. Lopes, A. B. Pereiro and L. P. N. Rebelo, RSC Adv., 2015, 5, 65337-65350.

36 N. V. Ghule, D. D. La, R. S. Bhosale, M. Al Kobaisi, A. M. Raynor, S. V. Bhosale and S. V. Bhosale, ChemistryOpen, 2016, 5, 157-163.

37 B.-P. Jiang, D.-S. Guo and Y. Liu, J. Org. Chem., 2010, 75, 7258-7264.

38 T. Mondal, T. Sakurai, S. Yoneda, S. Seki and S. Ghosh, Macromolecules, 2015, 48, 879-888.

39 H. Shao, T. Nguyen, N. C. Romano, D. A. Modarelli and J. R. Parquette, J. Am. Chem. Soc., 2009, 131, 16374-16376.

40 S. Basak, N. Nandi, A. Baral and A. Banerjee, Chem. Commun., 2015, 51, 780-783.

41 S. Ghosh, X.-Q. Li, V. Stepanenko and F. Würthner, Chem.Eur. J., 2008, 14, 11343-11357.

42 S. Yagai, T. Seki, T. Karatsu, A. Kitamura and F. Würthner, Angew. Chem., Int. Ed., 2008, 47, 3367-3371.

43 P. Rajdev, M. R. Molla and S. Ghosh, Langmuir, 2014, 30, 1969-1976.

44 C. Reichardt, Solvents and Solvent Effect in Organic Chemistry, Wiley-VCH, Weinheim, Germany, 2003.

45 C. Baddeley, Z. Yan, G. King, P. M. Woodward and J. D. Badjić, J. Org. Chem., 2007, 72, 7270-7278.

46 T. Pinault, B. Isare and L. Bouteiller, ChemPhysChem, 2006, 7, 816-819.

47 T. F. A. De Greef, M. M. J. Smulders, M. Wolffs, A. P. H. J. Schenning, R. P. Sijbesma and E. W. Meijer, Chem. Rev., 2009, 109, 5687-5754.

48 R. B. Martin, Chem. Rev., 1996, 96, 3043-3064.

49 Z. Chen, A. Lohr, C. R. Saha-Moller and F. Wurthner, Chem. Soc. Rev., 2009, 38, 564-584.

50 F. Aparicio, E. Matesanz and L. Sánchez, Chem.-Eur. J., 2014, 20, 14599-14603.

51 X. Lin, M. Hirono, T. Seki, H. Kurata, T. Karatsu, A. Kitamura, D. Kuzuhara, H. Yamada, T. Ohba, A. Saeki, S. Seki and S. Yagai, Chem.-Eur. J., 2013, 19, 6561-6565.

52 M. R. Molla and S. Ghosh, Chem. Mater., 2011, 23, 95-105.

53 M. M. J. Smulders, M. M. L. Nieuwenhuizen, T. F. A. de Greef, P. van der Schoot, A. P. H. J. Schenning and E. W. Meijer, Chem.-Eur. J., 2010, 16, 362-367.

54 Y. Xiong, M. Wang, X. Qiao, J. Li and H. Li, Tetrahedron, 2015, 71, 852-856.

55 J. Dupont, Acc. Chem. Res., 2011, 44, 1223-1231. 